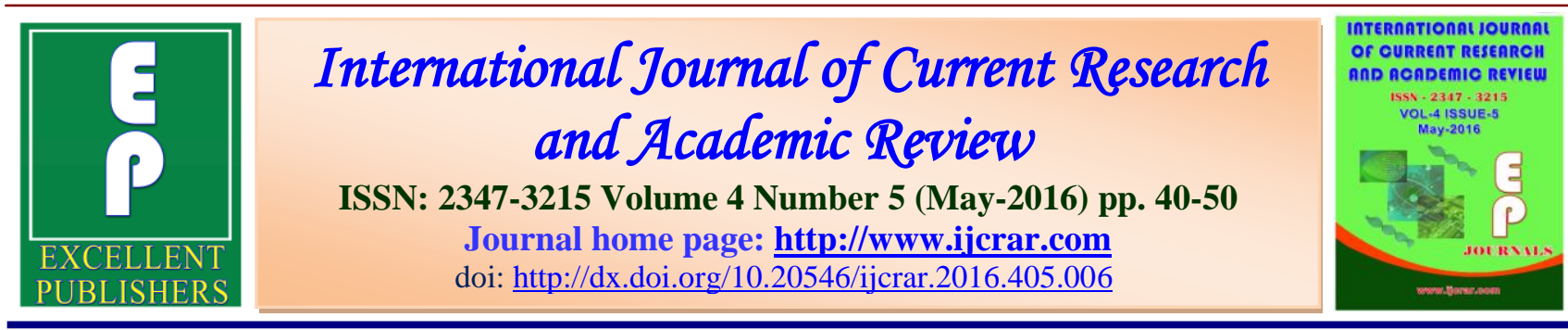

\title{
Spirometric Profile of Congolese Children and Adolescents in Rural and Urban Areas
}

Bazaba Kayilou Jean Michel ${ }^{1}$, Moussouami Simplice Innocent ${ }^{{ }^{*}}$, Massamba Alphonse ${ }^{1}$, M'Pemba loufoua Anne Berthe ${ }^{2}$, Mabiala babela Jean Robert ${ }^{2}$, Packa Tchissambou Bernard 1 , Kayembe ntumba Jean Marie ${ }^{3}$ and Senga Prosper ${ }^{4}$

${ }^{1}$ Laboratoire de Physiologie de l'Effort et de Biomécanique, Institut Supérieur d'Education Physique et Sportive, Université Marien Ngouabi, Brazzaville (Congo)

${ }^{2}$ Service de pédiatrie, Centre Hospitalier et Universitaire de Brazzaville, Congo

${ }^{3}$ Service de Pneumologie (Service du Pr KAYEMBE), Cliniques Universitaires de Kinshasa, Kinshasa, République Démocratique du Congo

${ }^{4}$ Professeur Emérite de Pédiatrie, Faculté des Sciences de la Santé, Université Marien Ngouabi, Brazzaville (Congo)

*Corresponding author

\section{\begin{tabular}{l|l} 
KEYWORDS & A B S T R A C T
\end{tabular}}

Spirometric

profile,

schoolchild,

area,

Congo
No local spirometric standards exist in Congo (Brazzaville), usable in paediatric pneumology. To determine the values of forced vital capacity, maximal expiratory volume per second and peak expiratory flow in the children and teenagers of the rural and urban areas and to establish spirometric reference equations according to the anthropometric variables. In this longitudinal study, almost 11994 Congolese pupils from 9 to 17 years old were recruited. They were divided into two groups, 6475 subjects living in urban area and 5519 in rural area. The following spirometric parameters were measured: forced vital capacity, maximal expiratory volume per second and peak expiratory flow using a portable spirometer. Partial Least Square regression model was applied to the data to establish the spirometric reference equations. No significant difference was found between the two areas, excluded for the peak expiratory flow. Values of the children resulting from rural area versus those of urban area were at the 9 years age: $0.741 \mathrm{vs} 0.851$ for forced vital capacity, $0.641 \mathrm{vs} 0.741$ for maximal expiratory volume per second, $1.04 \mathrm{l} / \mathrm{s}$ vs $1.12 \mathrm{l} / \mathrm{s}$ for peak expiratory flow. With the 17 years age, values were $2.50 \mathrm{l} v \mathrm{~s} 2.26 \mathrm{l}$ for forced vital capacity, 1.921 vs 1.761 for maximal expiratory volume per second, $2.27 \mathrm{l} / \mathrm{s}$ vs 3.0 1/s for peak expiratory flow. Positive correlations were found between each spirometric variable and anthropometric parameters (age, height, weight). The equations of prediction were specific of each variable, according to area and sex. The spirometric data obtained in congolese pupils could constitute a useful tool to follow pulmonary development and to diagnose the potential respiratory disorders in the two areas. 


\section{Introduction}

Pulmonary function tests are used to assess airway obstruction, bronchial hyperresponsiveness, restrictive syndromes and limitations on the exercise as can be observed in the practice of sport and physical activity (APS) in context school. During growth, lung volumes and peak flows are expired modified morphology, itself dependent on heredity, hormonal activity and socioeconomic status (Degrood et al., 1986). This is the case of forced vital capacity (FVC), forced expiratory volume in one second (FEV), and peak expiratory flow (PEF). These parameters are based on age, height, weight, gender, ethnicity and the surrounding environment (Harik- Khan et al., 2004). Indeed, the literature data show large differences between populations (Subbarao et al., 2004). The differences are explained by technical protocols used by the disparity of samples, as well as by differences in socio-economic and environmental (Ip et al., 2000).

Congo (Brazzaville), Central African countries populated by 3,217,568 inhabitants and consists of 257 ethnic groups, has a human development index (HDI) of 1.30 ; which ranks 137th in the world ranking in relation to sustainable development by 2011 (United Nations Development Programme, 2011). The life of the population is characterized by persistent poverty, the result of a combination of factors : the economic crisis, poor distribution of oil revenues, the mismanagement of national heritage. Added to this are the still visible consequences of the 1993 socio- political unrest and 1998 that caused the displacement of Southeast Congo populations, the destruction of basic infrastructure and agro-pastoral production, hence malnutrition populations.
So undernourishment of people, including disadvantaged social groups, calls a more scientific. This has implications for the physical fitness of children, the enrollment rate in Congo is $96 \%$ (Ministère et al., 2013). The physical exercises practiced as part of the physical education and sports (EPS) specifically solicit the respiratory system. If official instructions mandating the teaching of physical education and sport 6 years (primary school) to 18 (high school), however there is a lack of sports medical examinations to indicate or indicate against the practice sport and physical activity. Now this period is characterized by the development of secondary sexual characteristics, the acquisition of reproductive function, morphological and psychological changes.

In addition, the age of onset of morphological changes and the flow rate of a next stage in the development stage vary from child to child, depending on the sex. In addition, the literature shows that the lung is sensitive to environmental factors. In this context, the definition of respiratory function parameters standards remains a topical issue worldwide. (Plantier, 2013) In Congo, the development of pneumopédiatrie and exercise physiology has established the first reference values for lung volumes and maximum flow rates expired. These respiratory values are those reported by Packa-Tchissambou et al among 780 students from 9 to 17 years in Brazzaville. (Packa- Tchissambou et al., 2009) However, the selection of topics in this work was based on a transversal choice for convenience.

This study therefore proposes, from a sample of 11,994 subjects, two main objectives: to analyze the influence of age, sex and living environment (urban versus rural) on spirometric profile of Congolese 
Int.J.Curr.Res.Aca.Rev.2016; 4(5): 40-50

children and establish prediction equations said spirometric variable depending morphometric data.

\section{Material and Methods}

\section{Sampling}

The study, longitudinal, was conducted from February 2010 to February 2013 in Brazzaville (Congo political capital, populated by $1,037,112$ inhabitants) and Pointe Noire (the economic capital of 794 628 inhabitants) cities constituting the urban (MU). Rural (MR) was represented by 23 towns in the hinterland, located in 7 departments of the 10 in the country. The sampling method, by strattes, were adopted, the clusters are represented by school districts, schools and classrooms. The recruitment of the localities of the MR was based on two criteria: (1) the number of local residents who could not exceed 5,000 inhabitants; (2) data from the Ministry of Planning on the level of impoverishment of the population. After a random 1/10, 31 facilities were selected in urban areas and 17 in rural areas, all within 25 school districts. However, the agreement of the head teacher was a precondition for participation in the study. This led to 14 selected schools of general education and technology in ten departments.

The initial size of the school population retention in 2010 was 12365 pupils aged 9 to 17 years. After a history performed by health personnel (general practitioners) of each locality, were excluded from the sample lost to after one year, subjects with respiratory diseases patent, locomotor, cardiovascular, visual, auditory or other pathologies against-showing the practice of EPS. All the children were not trained; the only sport boiled down to PSE in schools. Definitely, a workforce of 12,725 students in 2010 included in the study, only 11994 patients (5918 boys and 6076 girls) participated fully in the study in 2013, a loss of $5.7 \%$ after 3 years. These subjects were divided into $6458 \mathrm{MU}$ children (3194 boys and 3502 girls) and 5536 of the MR (2714 boys and 2574 girls). The average age of children of both sexes was for males $13.9 \pm$ 0.4 years in MU against $14.1 \pm 1.1$ years in $\mathrm{MR}$, and for females $13.9 \pm 0.8$ years MU versus $13.7 \pm 0.4$ years in MR. The size, both sexes ranged from $1.31 \mathrm{~m}$ (9 years) to $1.72 \mathrm{~m}$ (17 years), body weight between $26.1 \mathrm{~kg}$ (9 years) and $53.8 \mathrm{~kg}$ (17 years).

\section{Protocol Data Collection and Variables Studied}

Anthropometric measurements (height, weight) were performed according to the proposed technique by Lohman et al. The variables studied were limited to age, gender, height, weight and constant spirometry (FVC, FEV, PEF). These were measured using a portable spirometer of Autospiro PAL-type ( Minato, Japan), in subjects sitting. All data were recorded each year and at the same time, between 8 h00 and h00 10 by the same physician for a given institution, according to the protocols of the American Thoracic Society, ATS (1995). For this, 15 GPs of the selected localities were required for the collection in the various selected schools.

\section{Statistical Analysis}

The results were processed using Mathcad software, version 8.2. For analysis of data, methods of descriptive and inferential statistics were used. Quantitative values are expressed as mean \pm standard deviation. The Student t test for large samples was used to compare two means. Regarding the establishment of predictive statistical relationships spirometric values based on anthropometric data, statistical regression 
PLS (Partial Least Square Regression) was used, through the Partial Triadic Analysis (ATP) (17-19). In the operating procedure of the ATP, the relationship between trade and infrastructure are determined by the correlation coefficient $r$ between the weight of five anthropometric variables (age, weight, height, chest circumference inspiratory, expiratory chest girth) and three spirometric variables. The threshold of statistical tests of all significance was set at $5 \%$.

\section{Results and Discussion}

The mean changes in vital capacity of boys and girls are reported in Table I. The vital capacity was steadily increasing from 9 to 17 years in both sexes, regardless of the living environment. For boys, the growth amounted to $+69.3 \%$ respectively in MR and $+65.7 \%$ in MU. Regardless of age, differences in values between the two media proved all non-significant ( $\mathrm{p}>0.05$ ). Regarding girls, deviations from 9 to 17 years were $+71.8 \%$ in MR against $+58.3 \%$ in MU. The peaks found at the age of 17 years: $2.27 \mathrm{l}$ and $1.991 \mathrm{MU}$ MR. No significant difference existed between the subjects of the two media, except for the same age at the age of 17 years where vital capacity daughters MR proved superior $(\mathrm{p}=$ 0.047).

The FEV values also followed an upward trend from 9 to 17 years, regardless of sex and living environment (Table II). The maximum values were, respectively boys to $2.29 \pm 0.56$ in the MU against $2.19 \pm 0.62$ in the MR, for girls $1.56 \pm 0.601$ and $1.33 \pm$ MR 0.53 in the MU. The variances of 9 to 17 were around boys in MR $+68.5 \%$ and $64.8 \%$ in MU; in girls, they amounted to + $64.1 \%$ in MR against $+45.9 \%$ in MU. No significant difference was found from one medium to another, for a similar age.
Regarding the DEP, there was also an increase of the values of 9 to 17 years for boys and girls from rural and urban areas (Table III). The respective growth rates were in the boys $+54.7 \%$ in MR and $+56.3 \%$ in MU. Maximum values were recorded among boys (2.6 l / s versus $1.91 / \mathrm{s})$; the differences in mean values between the two media, for the same age were all significant $(\mathrm{p}<0.05)$.

Moreover, the graphical output of ATP (Figure 1) showed stronger correlations between spirometric and anthropometric variables urban ( $\mathrm{r}$ between 0.4554 and 0.863). PLS regression equations (predictive equations) measuring the contribution of the variables age, height and weight to the construction of spirometric variables $(\mathrm{CV}$, FEV and PEF) are contained in Table IV. It appears from the examination of this table for the masculine gender $r$ coefficients of variable size in the $\mathrm{CV}$ equations and $\mathrm{FEV}$ were, respectively, 0.62 and 0.75 . Thereby varying size could not be ruled out of these equations. Similarly, the value of the correlation coefficient $r$ of the variable weight in the equation DEP, although relatively small $(\mathrm{r}=0.17)$, not allowed to remove this variable in this equation. For the female gender, the $r$ coefficients of the variable age in the $\mathrm{CV}$ equations and $\mathrm{FEV}$, between 0.13 and 0.35 , justified the inclusion of the latter in the equations. Finally, the coefficient on the variable weight in the DEP equation, equal to 0.31 , also did not allow to rule out this variable in the equation.

The aim of this study was to evaluate spirometric values of Congolese children of rural and urban areas and to identify factors contributing to differentiate the subjects of the two media, including anthropometric level. It appears from this study that the vital capacity of the boys of rural and urban areas 
increases with age (Table I); however, the values recorded for boys in rural areas are higher than those of boys in urban areas. About girls, no difference was found between the two media for the same age. The study FEV (Table II) also shows a steady increase in values in both environments, together with a similarity to age. At the DEP (Table III), the data also indicate an increase in value with age. However, the comparison of data shows a clear superiority of the values of boys and girls in urban areas. Finally, each spirometric variable depends on the anthropometric data (staturo-weight and chest), variable relationship by area (Table IV).

This study presents some limitations, however. The first reports of the lack of evaluation of the level of pubertal maturation, explained by the absence of a rural endocrinologist. Or the slope of increase of each ventilatory vary depending of the size varies from pubertal stage to another in both sexes.

The second limitation relates to the lack of comparison of spirometric data of our subjects with the theoretical values of ATS or the European Respiratory Society ERS (1993). Nowadays, the only standards are adapted to western Congo curves, such as those of the ATS (1995). The third limitation is the type of device used. More reliable spirometric values are determined objectively laboratory lung explorations, including a computer controlled spirometric system and coupled to a pneumotachograph. This investigation is, to our knowledge, the first to study the spirometric profile of school children Congolese rural and urban areas. She is among the few reports on the impact of the environment on respiratory variables involved in the child's physical fitness. A second strength of the study is related to the large size of the sample. Indeed, a recent study (Quanjer et al., 2011) which focused on the required number of subjects to validate the reference values reported a population of at least 150 boys and 150 girls, to avoid differences due to a sampling error. The sample size $(\mathrm{n}=11$ 994) is higher than those of other studies in healthy subjects of comparable age bracket: Kaditis et al in Italy $(\mathrm{n}=152)$, Shamssain $e t$ $a l$ in Libya $(\mathrm{n}=208)$, Trabelsi et al in Tunisia $(\mathrm{n}=756)$, Tsai et al in Taiwan $(\mathrm{n}=$ 309). Moreover, another strength of the study lies on establishing spirometric variables prediction equations based on anthropometric variables within the Congolese media using the statistical method of PLS regression. The choice of this mathematical model is based on four factors: the sharp explained variation in the dependent variable, the determination coefficient ( $\mathrm{r} 2$ ), the constancy of the residual standard deviation (RSD) and the low standard error. The confidence interval (CI) of employment associated values of this model (Hanafi et al., 2006): 95\% CI $=1.643$ RSD.

Our study has established spirometry reference values measured on a highly representative sample of a Congolese population of healthy students. The selection was made in schools of first and second degree of the different departments, so the main ethnic groups in Congo. Our results confirm that the $\mathrm{VC}, \mathrm{FEV}$ and $\mathrm{PEF}$ are a subject according to age, gender, ethnicity and its staturo-weight characteristics. Compared to age, this differentiation is due to the transition from infancy to the teen, characterized by increased lung volumes with increasing the size and weight. The significant increase in FVC and FEV depending on the size in both sexes $(r=0.73$ for boys and 0.68 for girls) can be explained by the bronchial and alveolar development 
during growt alongside the musculoskeletal growth of the chest and expand the intercostal spaces. This observation is valid in both sexes, was described in other African studies (Shamssain et al., 1988). For example, the study of Trabelsi et al., in Tunisia (2004) notes that morphometric factors (gender, height, weight, chest expansion) are most closely associated parameters to variable ventilation for both sexes. These observations also support those Dufetel et al. Togolese in children and PackaTchissambou et al., (2009)

Table.1 Comparison of the mean values of forced vital capacity (C.V.F. in 1) of boys and girls of rural and urban

\begin{tabular}{|c|c|c|c|c|c|c|}
\hline \multicolumn{4}{|c|}{ Boys } & \multicolumn{3}{|c|}{ Girls } \\
\hline Age & MR & $\mathbf{M U}$ & $\mathbf{p}$ & MR & MU & $\mathbf{p}$ \\
\hline 9 years & $\begin{array}{c}\mathbf{0 , 8 4} \pm 0,28 \\
(n=365)\end{array}$ & $\begin{array}{c}\mathbf{0 , 8 7} \pm \mathbf{0 , 4 0} \\
(\mathrm{n}=\mathbf{4 3 1})\end{array}$ & $>0,05$ & $\begin{array}{c}\mathbf{0 , 6 4} \pm 0,3 \\
(\mathrm{n}=343)\end{array}$ & $\begin{array}{c}\mathbf{0 , 8 3} \pm 0,44 \\
(n=436)\end{array}$ & $>0,05$ \\
\hline 10 years & $\begin{array}{c}\mathbf{0 , 8 4} \pm 0,35 \\
(n=349)\end{array}$ & $\begin{array}{c}0,74 \pm 0,31 \\
(n=422)\end{array}$ & $>0,05$ & $\begin{array}{c}\mathbf{0 , 8 5} \pm \mathbf{0 , 3 8} \\
(\mathrm{n}=\mathbf{3 3 0})\end{array}$ & $\begin{array}{c}1,17 \pm 0,74 \\
(n=417)\end{array}$ & $>0,05$ \\
\hline 11 years & $\begin{array}{c}1,15 \pm 0,4 \\
(n=337)\end{array}$ & $\begin{array}{c}1,17 \pm 0,48 \\
(n=413)\end{array}$ & $>0,05$ & $\begin{array}{c}1,31 \pm 0,52 \\
(n=322)\end{array}$ & $\begin{array}{c}1,01 \pm 0,48 \\
(n=402)\end{array}$ & $>0,05$ \\
\hline 12 years & $\begin{array}{c}1,17 \pm 0,52 \\
(n=315)\end{array}$ & $\begin{array}{c}1,16 \pm 0,57 \\
(n=401)\end{array}$ & $>0,05$ & $\begin{array}{c}1,16 \pm 0,57 \\
(n=314)\end{array}$ & $\begin{array}{c}1,11 \pm 0,42 \\
(n=395)\end{array}$ & $>0,05$ \\
\hline 13 years & $\begin{array}{c}1,27 \pm 0,55 \\
(n=312)\end{array}$ & $\begin{array}{c}1,42 \pm 0,47 \\
(n=384)\end{array}$ & $>0,05$ & $\begin{array}{c}1,23 \pm 0,64 \\
(n=298)\end{array}$ & $\begin{array}{c}1,02 \pm 0,54 \\
(n=389)\end{array}$ & $>0,05$ \\
\hline 14 years & $\begin{array}{c}1,75 \pm 0,67 \\
(n=294)\end{array}$ & $\begin{array}{c}1,63 \pm 0,38 \\
(n=369)\end{array}$ & $>0,05$ & $\begin{array}{c}1,47 \pm 0,46 \\
(n=283)\end{array}$ & $\begin{array}{c}1,66 \pm 0,51 \\
(n=382)\end{array}$ & $>0,05$ \\
\hline 15 years & $\begin{array}{c}2,19 \pm 0,72 \\
(n=273)\end{array}$ & $\begin{array}{c}1,92 \pm 0,51 \\
(n=332)\end{array}$ & $>0,05$ & $\begin{array}{c}1,82 \pm 0,48 \\
(n=271)\end{array}$ & $\begin{array}{c}1,69 \pm 0,5 \\
(n=376)\end{array}$ & $>0,05$ \\
\hline 16 years & $\begin{array}{c}2,56 \pm 0,68 \\
(n=268)\end{array}$ & $\begin{array}{c}2,41 \pm 0,53 \\
(n=316)\end{array}$ & $>0,05$ & $\begin{array}{c}1,84 \pm 0,53 \\
(n=261)\end{array}$ & $\begin{array}{c}1,98 \pm 0,66 \\
(n=373)\end{array}$ & $>0,05$ \\
\hline 17 years & $\begin{array}{c}2,74 \pm 0,58 \\
(n=201)\end{array}$ & $\begin{array}{c}2,54 \pm 0,61 \\
(n=219)\end{array}$ & $>0,05$ & $\begin{array}{c}2,27 \pm 1,89 \\
(n=152)\end{array}$ & $\begin{array}{c}1,99 \pm 0,53 \\
(n=332)\end{array}$ & $<0,01$ \\
\hline
\end{tabular}

Table.2 Comparison of average values of the maximum expiratory volume (in V.E.M.S. 1) of boys and girls in urban rural

\begin{tabular}{|c|c|c|c|c|c|c|}
\hline \multirow[b]{2}{*}{ Age } & \multicolumn{3}{|c|}{ Boys } & \multicolumn{3}{|c|}{ Girls } \\
\hline & MR & MU & $\mathbf{P}$ & MR & MU & $\mathbf{p}$ \\
\hline 9 years & $\begin{array}{c}0,72 \pm 0,24 \\
(n=365)\end{array}$ & $\begin{array}{c}\mathbf{0 , 7 7} \pm \mathbf{0 , 4 0} \\
(\mathrm{n}=\mathbf{4 3 1})\end{array}$ & $>0,05$ & $\begin{array}{c}0,56 \pm 0,29 \\
(n=343)\end{array}$ & $\begin{array}{c}\mathbf{0 , 7 2} \pm 0,37 \\
(n=436)\end{array}$ & $>0,05$ \\
\hline 10 years & $\begin{array}{c}\mathbf{0 , 6 9 \pm 0 , 2 6} \\
(n=439)\end{array}$ & $\begin{array}{c}0,66 \pm 0,28 \\
(n=422)\end{array}$ & $>0,05$ & $\begin{array}{c}\mathbf{0 , 6 7 \pm 0 , 2 3} \\
(\mathrm{n}=\mathbf{3 3 0})\end{array}$ & $\begin{array}{c}\mathbf{0 , 8 7} \pm 0,43 \\
(n=417)\end{array}$ & $>0,05$ \\
\hline 11 years & $\begin{array}{c}\mathbf{0 , 9 7 \pm 0 , 3 9} \\
(\mathbf{n}=\mathbf{3 3 7})\end{array}$ & $\begin{array}{c}\mathbf{0 , 9 8} \pm 0,41 \\
(n=413)\end{array}$ & $>0,05$ & $\begin{array}{c}\mathbf{0 , 9 6 \pm 0 , 4 6} \\
(\mathrm{n}=322)\end{array}$ & $\begin{array}{c}0,91 \pm 0,44 \\
(n=402)\end{array}$ & $>0,05$ \\
\hline 12 years & $\begin{array}{c}\mathbf{0 , 9 8} \pm 0,47 \\
(\mathrm{n}=315)\end{array}$ & $\begin{array}{c}0,98 \pm 0,512 \\
(n=402)\end{array}$ & $>0,05$ & $\begin{array}{c}0,99 \pm 0,46 \\
(n=314)\end{array}$ & $\begin{array}{c}0,95 \pm 0,40 \\
(n=389)\end{array}$ & $>0,05$ \\
\hline 13 years & $\begin{array}{c}1,16 \pm 0,48 \\
(n=312)\end{array}$ & $\begin{array}{c}1,31 \pm 0,41 \\
(n=384)\end{array}$ & $>0,05$ & $\begin{array}{c}1,10 \pm 0,52 \\
(n=298)\end{array}$ & $\begin{array}{c}\mathbf{0 , 9 7 \pm 0 , 5 3} \\
(\mathrm{n}=389)\end{array}$ & $>0,05$ \\
\hline 14 years & $\begin{array}{c}1,45 \pm 0,63 \\
(n=294)\end{array}$ & $\begin{array}{c}1,48 \pm 0,389 \\
(n=369)\end{array}$ & $>0,05$ & $\begin{array}{c}1,19 \pm 0,43 \\
(n=283)\end{array}$ & $\begin{array}{c}1,48 \pm 0,47 \\
(n=382)\end{array}$ & $>0,05$ \\
\hline 15 years & $\begin{array}{c}2,00 \pm 0,92 \\
(n=273)\end{array}$ & $\begin{array}{c}1,69 \pm 0,43 \\
(n=332)\end{array}$ & $>0,05$ & $\begin{array}{c}1,35 \pm 0,3 \\
(n=271)\end{array}$ & $\begin{array}{c}1,51 \pm 0,50 \\
(n=276)\end{array}$ & $>0,05$ \\
\hline 16 years & $\begin{array}{c}2,19 \pm 0,63 \\
(n=268)\end{array}$ & $\begin{array}{c}2,00 \pm 0,56 \\
(n=316)\end{array}$ & $>0,05$ & $\begin{array}{c}1,39 \pm 0,47 \\
(n=261)\end{array}$ & $\begin{array}{c}1,64 \pm 0,56 \\
(n=373)\end{array}$ & $>0,05$ \\
\hline 17 years & $\begin{array}{c}2,29 \pm 0,56 \\
(n=201)\end{array}$ & $\begin{array}{c}2,19 \pm 0,619 \\
(n=219)\end{array}$ & $>0,05$ & $\begin{array}{c}1,56 \pm 0,6 \\
(n=152)\end{array}$ & $\begin{array}{c}1,33 \pm 0,53 \\
(n=332)\end{array}$ & $>0,05$ \\
\hline
\end{tabular}


Int.J.Curr.Res.Aca.Rev.2016; 4(5): 40-50

Table.3 Comparison of average values of peak expiratory flow ( D.E.P in $1 / \mathrm{s}$ ) for boys and girls of the rural and urban areas

\begin{tabular}{|c|c|c|c|c|c|c|}
\hline \multicolumn{4}{|c|}{ Boys } & \multicolumn{3}{|c|}{ Girls } \\
\hline Age & MR & MU & $\mathbf{p}$ & MR & MU & $\mathbf{p}$ \\
\hline 9 years & $\begin{array}{c}1,17 \pm 0,33 \\
(n=365)\end{array}$ & $\begin{array}{c}1,15 \pm 0,40 \\
(n=431)\end{array}$ & $<0,05$ & $\begin{array}{c}\mathbf{0 , 9 2} \pm 0,50 \\
(n=343)\end{array}$ & $\begin{array}{c}1,07 \pm 0,41 \\
(n=436)\end{array}$ & $<0,05$ \\
\hline 10 years & $\begin{array}{c}1,25 \pm 0,58 \\
(n=349)\end{array}$ & $\begin{array}{c}1,25 \pm 0,63 \\
(n=422)\end{array}$ & $<0,01$ & $\begin{array}{c}1,09 \pm 0,35 \\
(n=330)\end{array}$ & $\begin{array}{c}1,66 \pm 0,64 \\
(n=417)\end{array}$ & $<0,02$ \\
\hline 11 years & $\begin{array}{c}1,67 \pm 0,64 \\
(n=337)\end{array}$ & $\begin{array}{c}1,75 \pm 0,75 \\
(n=413)\end{array}$ & $<0,02$ & $\begin{array}{c}1,56 \pm 0,64 \\
(n=322)\end{array}$ & $\begin{array}{c}1,09 \pm 0,25 \\
(n=402)\end{array}$ & $<0,02$ \\
\hline 12 years & $\begin{array}{c}1,49 \pm 0,47 \\
(n=315)\end{array}$ & $\begin{array}{c}1,72 \pm 0,69 \\
(n=401)\end{array}$ & $<0,02$ & $\begin{array}{c}1,59 \pm 0,83 \\
(n=314)\end{array}$ & $\begin{array}{c}1,67 \pm 0,64 \\
(n=395)\end{array}$ & $<0,05$ \\
\hline 13 years & $\begin{array}{c}1,73 \pm 0,65 \\
(n=312)\end{array}$ & $\begin{array}{c}1,95 \pm 0,86 \\
(n=384)\end{array}$ & $<0,05$ & $\begin{array}{c}1,97 \pm 0,32 \\
(n=298)\end{array}$ & $\begin{array}{c}1,42 \pm 0,50 \\
(n=389)\end{array}$ & $<0,02$ \\
\hline 14 years & $\begin{array}{c}2,01 \pm 0,38 \\
(n=294)\end{array}$ & $\begin{array}{c}2,41 \pm 0,22 \\
(n=369)\end{array}$ & $<0,02$ & $\begin{array}{c}1,67 \pm 0,25 \\
(n=283)\end{array}$ & $\begin{array}{c}2,37 \pm 0,83 \\
(n=382)\end{array}$ & $<0,01$ \\
\hline 15 years & $\begin{array}{c}2,03 \pm 0,42 \\
(n=273)\end{array}$ & $\begin{array}{c}2,83 \pm 0,56 \\
(n=332)\end{array}$ & $<0,05$ & $\begin{array}{c}1,73 \pm 0,12 \\
(n=271)\end{array}$ & $\begin{array}{c}2,41 \pm 0,36 \\
(n=276)\end{array}$ & $<\mathbf{0 , 0 2}$ \\
\hline 16 years & $\begin{array}{c}2,50 \pm 0,21 \\
(n=268)\end{array}$ & $\begin{array}{c}2,90 \pm 0,24 \\
(n=316)\end{array}$ & $<0,02$ & $\begin{array}{c}1,78 \pm 0,25 \\
(n=261)\end{array}$ & $\begin{array}{c}2,50 \pm 0,42 \\
(n=373)\end{array}$ & $<0,02$ \\
\hline 17 years & $\begin{array}{c}2,60 \pm 0,35 \\
(n=201)\end{array}$ & $\begin{array}{c}3,55 \pm 0,48 \\
(n=219)\end{array}$ & $<0,01$ & $\begin{array}{c}1,95 \pm 0,29 \\
(n=152)\end{array}$ & $\begin{array}{c}2,45 \pm 0,16 \\
(n=332)\end{array}$ & $<0,01$ \\
\hline
\end{tabular}

Table.4 Prediction equations (PLS) spirometric values

\begin{tabular}{ll}
\hline \multicolumn{1}{c}{ Boys } & \multicolumn{1}{c}{ Girls } \\
\hline Middle Urban & CVF $=0,005 \mathrm{~A}+0,013 \mathrm{~T}+0,0015 \mathrm{P}$ \\
$\mathrm{CVF}=0,129 \mathrm{~A}+0,003 \mathrm{~T}+0,023 \mathrm{P}$ & $\mathrm{VEMS}=0,005 \mathrm{~A}+0,014 \mathrm{~T}+0,0016 \mathrm{P}$ \\
$\mathrm{VEMS}=0,014 \mathrm{~A}+0,001 \mathrm{~T}+0,0044 \mathrm{P}$ & $\mathrm{DEP}=0,287 \mathrm{~A}+0,22 \mathrm{~T}+0,006 \mathrm{P}$
\end{tabular}

\section{Middle rural}

$\mathrm{CVF}=0,078 \mathrm{~A}-0,15 \mathrm{~T}+0,045 \mathrm{P}$

$\mathrm{CVF}=0,07 \mathrm{~A}+0,008 \mathrm{~T}+0,009 \mathrm{P}$

VEMS $=0,04 \mathrm{~A}+0,12 \mathrm{~T}+0,011 \mathrm{P}$

VEMS $=0,005 \mathrm{~A}+0,014 \mathrm{~T}+0,0016 \mathrm{P}$

$\mathrm{DEP}=0,125 \mathrm{~A}-0,013 \mathrm{~T}+0,002 \mathrm{P}$

$\mathrm{DEP}=0,287 \mathrm{~A}-0,022 \mathrm{~T}+0,006 \mathrm{P}$

Abbreviations: CV, vital capacity ; FEV, forced expiratory volume in one second ; DEP, peak expiratory flow ; A, age ; T, size ; P, body weight 
Figure.1 Analysis of correlations according compromise and intrastructure
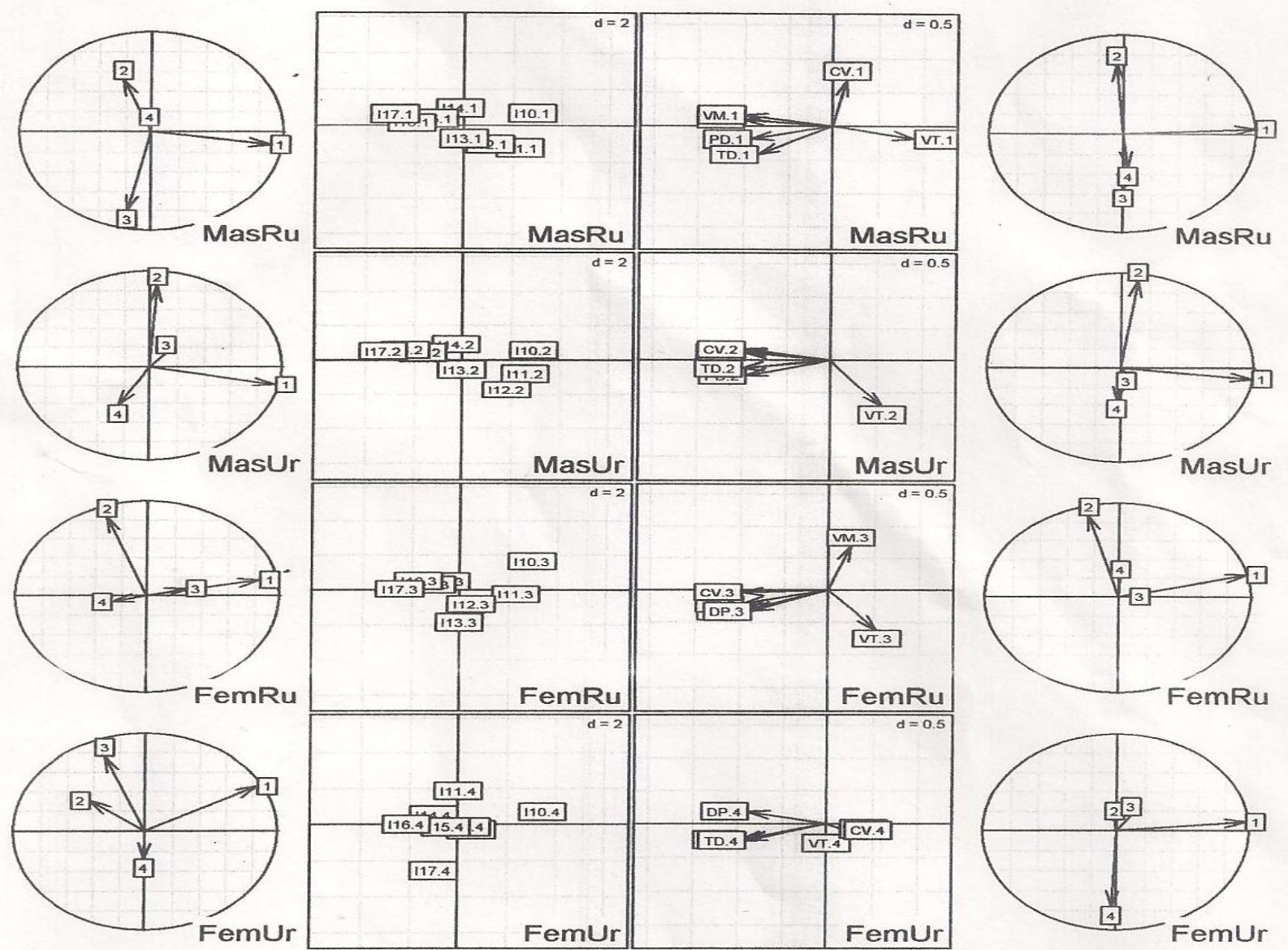

These authors have studied in 2009 in Brazzaville on spirometric profile Bantu Congolese children and adolescents aged 8 to 20 years. At the age of 8 , spirometric average values stood at $1.91(\mathrm{G})$ versus 1.81 (F) for the FVC, $1.51(\mathrm{G})$ against $1.61(\mathrm{~F})$ for FEV $2.61 / \mathrm{s}(\mathrm{G})$ versus $2.41 / \mathrm{s}(\mathrm{F})$ for DEP. At the age of 17, these values reached: $3.51(\mathrm{G})$ against $2.71(\mathrm{~F})$ for the FVC, 2.91 (G) against 2.51 (F) for FEV, $5.31 / \mathrm{s}(\mathrm{G})$ versus $4.41 / \mathrm{s}(\mathrm{F})$ for DEP. In our series, they rise in boys at the age of 9 years to 0.84 1 and $0.871 \mathrm{MR}$ MU for FVC, $1.561 \mathrm{MR}$ against 1.33 in the MU for FEV, $1.041 / \mathrm{s}$ MR against $1.111 / \mathrm{s}$ at MU for the DEP. At the age of 17 these values were $\$ 2.74$ in the MR and 2.54 in the MU for FVC, 2.291 and
$2.191 \mathrm{MR} \mathrm{MU}$ for FEV, 2.27 1 / s MR against $3.001 / \mathrm{s}$ at MU for the DEP.. Trabelsi et al, in Tunisian children (25) relate to the age of 17 values of $3.8 \pm 0.61$, for FEV $4.1 \pm 0.5 \mathrm{~s}$ and the DEP $37 \pm 1.21$ / s; by MU, found $2.5 \pm 0.7$ for the $\mathrm{CV}, 2.1 \pm$ 0.6 for the FEV and $3.4 \pm 1.31 / \mathrm{s}$ for the DEP. The differences in both Congo in Tunisia between children of the two media can, in no doubt, be due to food shortages or malnutrition and relatively low socioeconomic level in the hinterland. However, a high level of activity during childhood contributes to obtaining a pulmonary function than average. Thus, the pastoral activities carried out by children of MR associated with long travel between the 
village and the school on the one hand, and the fields of the other may explain the superiority of their FVC. However, in MU this would be the most developed sport; which would involve the shoulder girdle muscles.

In addition, there is a close connection between the ventilatory variables and physical activity. In addition, the age of onset of pubertal signs varies from child to child and gender. For example, Lounana et al noted in the Congo as age at menarche in girls sports is around 15.36 years against 13.78 years for sedentary. Now it is known that puberty is the period during which sexual maturation has an impact on the growth spurt. All these factors can then be discussed in the genesis of the differences between profiles Congolese spirometry Libyan Tunisia and Nigeria.

In this work, the DEP NCM of children is lower than that recorded in MU. This can be attributed a priori less pollution of the environment. However, a recent company in the Ivory Coast shows that cooking smoke study, particularly the outcome of firewood, has deleterious effects on lung function. In Congo, more than $4 / 5$ of rural families cook their meals in the evening or rainy days, using firewood inside poorly ventilated homes. Therefore, our assertions deserve to be put into perspective in view of air pollution observed in Brazzaville and Pointe-Noire. it comes from the relatively intense automobile traffic over the past decade and the oil industry (case of PointeNoire). Added to this is the consumption of tobacco, as reported Mabiala Babela et al., these authors report in 2008 a smoking prevalence of about $10.3 \%$ in brazzavilois children aged 10 to 19 years. Finally, multivariate analysis revealed a close link between the ventilatory variables and morphometric parameters (height, weight), not to mention the age and sex. Our prediction equations (Table $\mathrm{V}$ ) is therefore close to those of ERS (1993) for children 8 to 17 years. By cons, Bougrida et al (2008) in 208 Algerian children noted the variability of spirometric data by the combination of gender, age, size, body mass index and body surface. However, the study of correlations between these factors relate these bonds account for only $69-94 \%$ of the variability of spirometric data. Among the factors involved that make account for this variability, we note the differences in fat free mass, chest dimensions and pressure that respiratory muscles can produce. (1989)

\section{Conclusion}

This longitudinal survey has established profiles of forced vital capacity, forced expiratory volume in one second and peak expiratory flow rate in children and teenagers living in the Congolese town and countryside. However, further spirometric data deserve to be taken into account in order to have a full spirometric profile may influence the management strategies in pediatric pulmonology.

\section{Acknowledgements}

We are grateful to the Project LCS / GEP Congo and the Academy of Sciences of the Third World for their funding. We also thank all the doctors and school administrators without which this work would not have taken shape for their valuable collaboration.

\section{References}

American Thoracic Society. 1995. Standardisation of spirometric. Am. J. Respir. Crit. Care Med., 152: 1107-36.

Bougrida, M., Bourahli, M.K., Aissaoui, A., Rouatbi, S., Mehdioui, H., Saad, H.B. 2012. Valeurs de référence 
spirométriques des enfants de Constantine (Région de 1'Est Algérian).

Tunisie Médicale, 90(1): 51-61.

Courtex, D., Obert, P., Lecoq, A.M., Guenon, P., Koch, G. 1997. Effect of intensive swimming training on lung volumes, airway resistance and on the maximal expiratory flow-volume relationship in prepubertal girls. Eur. J. Appl. Physiol. Occup. Physiol., 76: 264-9.

De Groodt, E.G., Van Pelt, W., Borsboom, G.J.J.M,. Quanjer, P.H. 1989. Growth of lung and thorax dimensions during the pubertal growth spurt. Eur. Respir. J., 1: 102-8.

Degrood, E.G., Quanjer, P.H., Wise, M.E., Van Zomere, B.C. 1986. Changing relationships stature and lung Volumes during puberty. Respir. Physiol., 65: 139- 53.

Dockery, D.W., Ware, J.H., ferris, B.J.Jr, Speizer. F.E., Cook, N.R., Herman, S.M. 1982. Change in pulmonary function in children associated with air pollution episodes. J. Air Pollut. Control Assoc., 32: $937-42$.

Dufetel, P., Pigearias, B., Boutros Toni, F., Lonsdorfer, J. 1986. Valeurs de référence de la capacité vitale et du volume expiratoire maximal par seconde chez l'homme de 20 à 50 ans au sénégal. Med. Sport, 60: 186-191.

Glew, R.H., Kassan, H., Van der voort, J., Agaba, P.A., Harkinss, M., Vande, D.J. 2004. Comparison of pulmonary function between children living in rural and urban areas in northern Nigeria. Comment Int. Trop. Pediatr., 50(4): 21728.

Hanafi, R., Quannari, A. 2006. Regresssion analysis for count data analysis with applications. Ann. Inst. Statist. Math., 68: 1585-91.

Harik- Khan, R.I., Muller, D.C., Wise, R.A. 2004. Racial differences in lung function in african-american and white children: effect of anthropometric, socioeconomic, nutritional and environmental factors. Am. J. Epidemiol., 160: 893-900.
Ip, Ms, Karlbrg, E.M., Karlberg, J.P., Luk. K.D., Leong, J.C. 2000. Lung function reference values in Chinese children and adolescents in Hong Kong. I. Spirometric values and comparison with other populations. Am. J. Respir. Crit. Care Med., 162: 424- 9.

Kaditis, A.G., Gourgoulianis, K., Tsoutsou, P., et al. 2008. Spirometric values in Gypsy (Roma) children. Respir. Med., 102: 1321-8.

Karlberg, J. 2002. Secular trends in pubertal development. Horm. Res., 57: 72 p.

Kissita, G., kokonendji, C.C., Demetrio, C.G.B., Dossou Gbete, S. 2004. Regression linear models and extension. Statis. Oper. Res. Trans., 28: 201-14.

Kouassi, B., Horo, K., Ahui, B,. Godé, C., N'Guessan, L., Anon, J.C., et al. 2012. Manifestations cliniques liées à la fumée de cuisine chez les femmes en milieu africain. Rev. Mal. Respir., 29: 398- 403.

Ledowitz, M.D., Sherill, D.L. 1995. The assessment and interpretation of spirometry during the transition from childhood to adulthood. Pediar. Pulmonol., 19: 143-9.

Lohmann, T.G., Roche, A.F., Martorell, R. 1998. Anthropometric standardization reference manual. Champaign, Illinois: Human Kinetics, 184 p.

Lounana, J., Bantsimba, M., Silou, J., PackaTchissambou, B,. Medelli, J. 2002. Influence de la pratique sportive intensive et précoce sur l'âge à la menarche dans une population de femmes congolaises. Sci. Sports, 17: 1725.

Mabiala Babela, J.R., Mahoungou Guimbi, K.C., Massamba, A., Senga, P. 2008. Tabagisme chez l'adolescent à Brazzaville (Congo). Ann. Afr. Med., 1(9): 31- 39.

Ministère de l'Enseignement et Secondaire, Chargé de l'Alphabetisation. $\mathrm{La}$ scolarisation de l'enfant congolais en chiffres, année 2012. Brazzaville : Direction des Etudes et de la Planification, 57: 19- 30. 
Neve, V., Girard, F., Flahault, A., Boule, M. 2002. Lung and thorax development during adolescence: relationship with pubertal status. Eur. Respir. J., 20: 12928.

Packa- Tchissambou, B., Moulongo, A.G., Mizere, D., Rizet, R. 2009. Valeurs de référence spirométriques des enfants et adolescents bantous congolais. Dakar Médical, 54(2): 112-8.

Plantier, L. 2013. Définir la normalité des paramètres fonctionnels respiratoires : une question toujours d'actualité. Rev. Mal. Respir., 5: 45-48.

Quanjer, P.H., Stocks, J., Cole, T.J., Hall, G.L., Stanojevic, S. 2011. On behalf of the global lungs initiative. Influence of secular trends and sample size on reference equations for lung function tests. Eur. Respir. J., 37: 658-64.

Quanjer, P.H., Tammeling, G.J., Cotes, J.E., Petersen, O.F., Peslin, R., Yernault, J.C. 1993. Lung volume and forced ventilatory flows. Report Working Party Standardisation of lung function tests, European Respiratory Society. Eur. Respir. J., 16: 5-40.

Rojas- Martinez, R., Perez- Padilla, R., OlaizFernandez, G., Mendoza-Alvarado, L., Moreno- Macias, H., Fortoul, T., et al. 2007. Lung function growth in children with long- term exposure to air pollutants in Mexico City. Am. J. Respir. Crit. Care Med., 176: 377-84.

Shamssain, M.H., Thompson, J., Ogston, S.A. 1988. Forced expiratory indices in normal Libyan children aged 6-19 years. Thorax, 43: 467- 70.

Subbarao, P., Lebecque, P., Corey, M., Coates, A.L. 2004. Comparison of spirometric reference values. Pediatr. Pulmonol., 37: 515- 22.

Tanner, J.M. 1962. Growth at adolescence, $2^{\text {nd }}$ edn. Oxford: Blackwell.

Tenehaus, M., La regression, P.L.S., théorie et pratique. Paris: éditions Technip, 253 p.

Trabelsi, Y., Ben Saad, H., Tabka, Z., Gharbi, N., Bouchez Buvry, A., Richalet, J.P., Guenard, H. 2004. Spirometric reference values in tunisian children. Respir., 71: 511-8

Tsai, M.C., Jeng, M.J., Chang, H.L., et al. 2010. Spirometric reference equations for healthy children aged 6 to 11 years in Taiwan. J. Chin. Med. Assoc., 73: 21-8.

United Nations Development Programme. Human development report. 2011. Sustainability and equity. A better future for all. New York : Macmillan, $176 \mathrm{p}$.

Veeranna, N., Rao, Kr. 2004. A study of peak expiratory flow rates among tribal children of Mysore District. J. Indian Med. Assoc., 102: 357- 9.

World Health Organization. 1987. Air Quality Guidelines for Europe. Copenhagen, WHO Regional Office for Europe: WHO Regional Publications, European Series No. 23, 1987.

Zeltner, T.B., Burri, T.H. 1987. The postnatal development and growth of the human lung. II. Morphology. Respir. Physiol., 67: 269-82.

\section{How to cite this article:}

Bazaba Kayilou Jean Michel, Moussouami Simplice Innocent, Massamba Alphonse, M'Pemba loufoua Anne Berthe, Mabiala babela Jean Robert, Packa Tchissambou Bernard, Kayembe ntumba Jean Marie and Senga Prosper. 2016. Spirometric Profile of Congolese Children and Adolescents in Rural and Urban Areas. Int.J.Curr.Res.Aca.Rev.4(5): 40-50. doi: http://dx.doi.org/10.20546/ijcrar.2016.405.006 